\title{
Stability of EB When Cryostat Load is Applied
}

\author{
By \\ V. Guarino \\ Argonne National Laboratory \\ High Energy Physics Division \\ Argonne, IL 60439
}

June 23, 2004

\begin{abstract}
The submitted manuscript has been created by the University of Chicago as Operator

of Argonne National Laboratory

(“Argonne") under Contract No. W-31-

109-ENG-38 with the U.S. Department of

Energy. The U.S. Government retains for

itself, and others acting on its behalf,

a paid-up, nonexclusive, irrevocable

worldwide license in said article to

reproduce, prepare derivative works,

distribute copies to the public, and perform

publicly and display publicly, by or on
\end{abstract}

*Work supported in part by the U.S. Department of Energy, Division of High Energy Physics, under Contract W-31-109-ENG-38. 


\begin{abstract}
This report was prepared as an account of work sponsored by an agency of the United States Government. Neither the United States Government nor any agency thereof, nor The University of Chicago, nor any of their employees or officers, makes any warranty, express or implied, or assumes any legal liability or responsibility for the accuracy, completeness, or usefulness of any information, apparatus, product, or process disclosed, or represents that its use would not infringe privately owned rights. Reference herein to any specific commercial product, process, or service by trade name, trademark, manufacturer, or otherwise, does not necessarily constitute or imply its endorsement, recommendation, or favoring by the United States Government or any agency thereof. The views and opinions of document authors expressed herein do not necessarily state or reflect those of the United States Government or any agency thereof.
\end{abstract}

Available electronically at http://www.osti.gov/bridge/

Available for a processing fee to U.S. Department of Energy and its contractors, in paper, from:

U.S. Department of Energy

Office of Scientific and Technical Information

P.O. Box 62

Oak Ridge, TN 37831-0062

phone: (865) 576-8401

fax: (865) 576-5728

email: reports@adonis.osti.gov 
ANL-HEP-TR-04-65

\title{
Stability of EB When Cryostat Load is Applied
}

\author{
By \\ V. Guarino \\ Argonne National Laboratory \\ High Energy Physics Division \\ Argonne, IL 60439
}

June 23, 2004

*Work supported in part by the U.S. Department of Energy, Division of High Energy Physics, under Contract W-31-109-ENG-38. 


\title{
Stability of EB When Cryostat Load is Applied
}

\author{
Victor Guarino \\ Argonne National Laboratory \\ June 23, 2004
}

\section{Introduction}

The cryostat load will be transferred to the EB with 24 modules in place. It is important to know that the EB is stable in this situation and during the subsequent assembly of the remaining modules. Appendix 1 describes a static 2D analysis that was done to examine the stability of the EB with the cryostat load applied. The paper below discussed the implications of this analysis.

\section{EB Stability}

The chart below shows how the bottom swivel bolt force varies in the $2 \mathrm{D}$ static analysis as the number of modules increases and as a function of the location of the centroid of the top swivel bolt force. It can be seen that by module 48, the bottom swivel bolt force is in compression for the centroid of the top swivel bolt force being at 48 degrees or greater. However, if this centroid is located below 48 degrees, the 2D static analysis shows that contact will be lost on the bottom swivel bolt, because the force goes into tension.

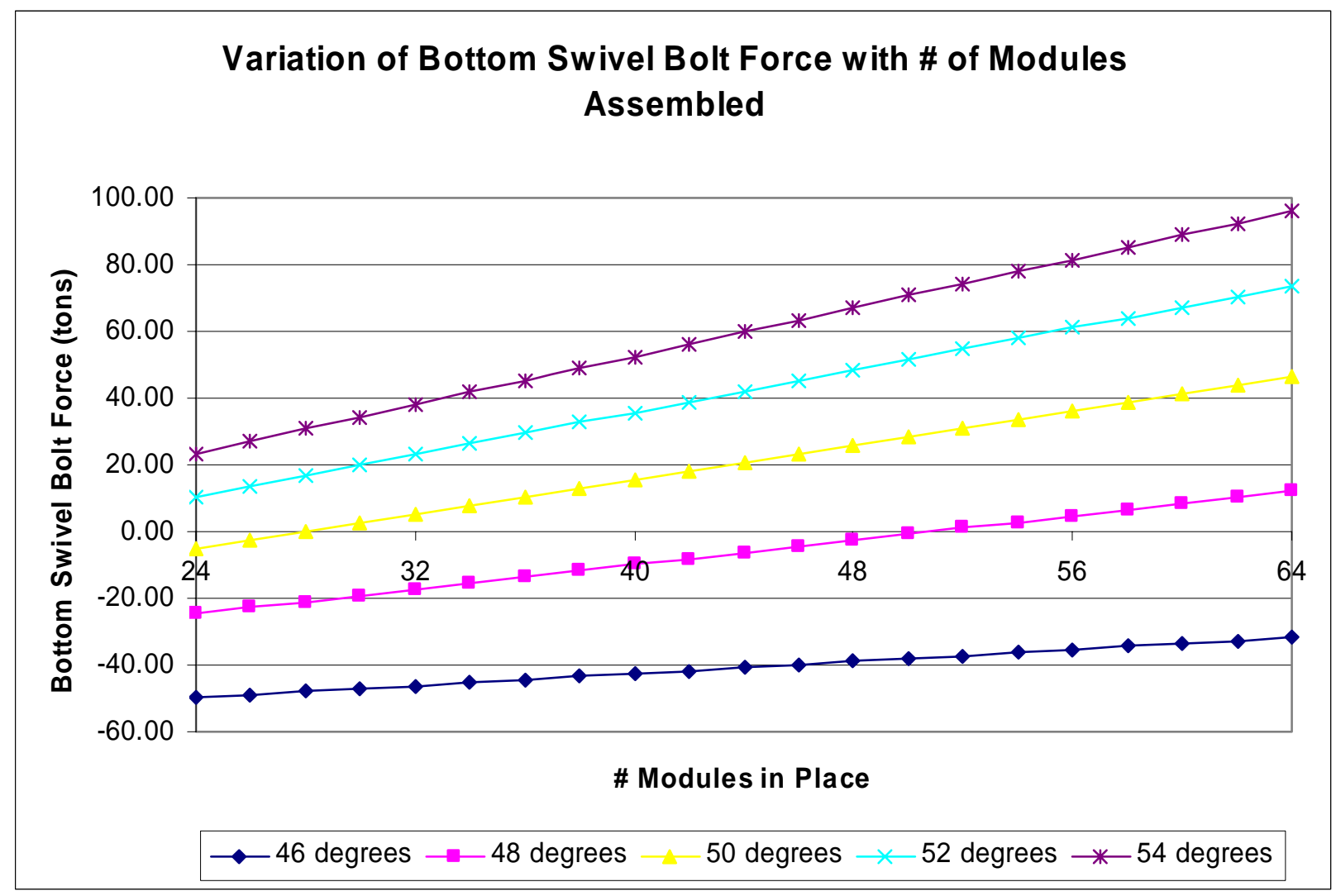

For each number of modules assembled, there is an angle for the top swivel bolt, at which equilibrium occurs with the force on the bottom swivel bolt, F1, equal to zero. This angle (stability angle) represents the point where the bottom swivel bolt must go from compression to tension in order to maintain equilibrium. The chart below shows how this stability angle changes with the number of modules in place. 


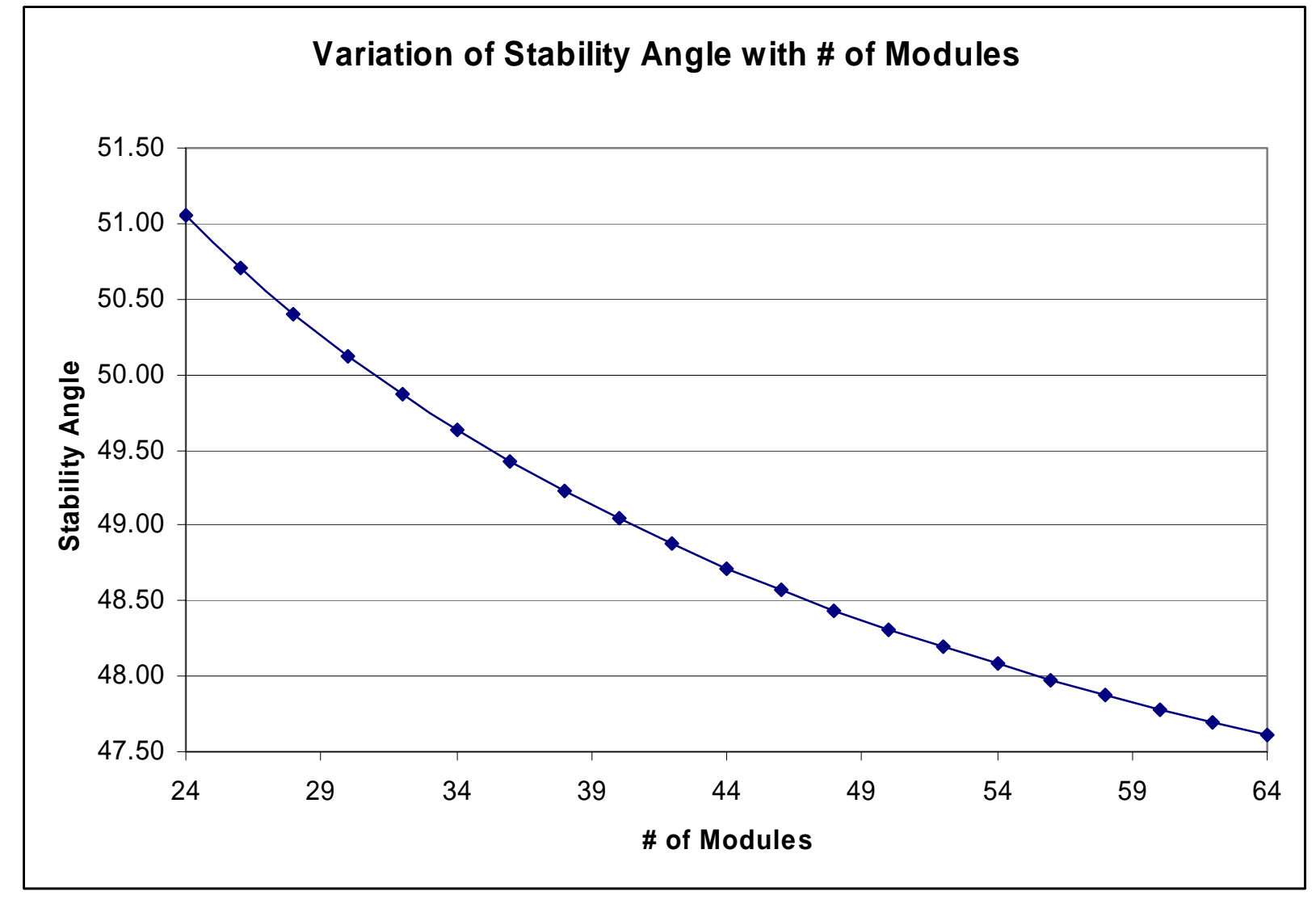

How does this compare with the 3D FEA model?

The charts below show the distribution of swivel bolt forces from the 3D FEA analysis for 24, 32, 48, and 64 modules in place.

\author{
24 Modules in Place with Cryostat Load \\ Bottom Swivel Bolt Force $=10$ tons \\ Sum of Top Swivel Bolt Force $=139$ tons \\ Angle to Centroid of Top Swivel Bolt Force $=51.86$ degrees
}

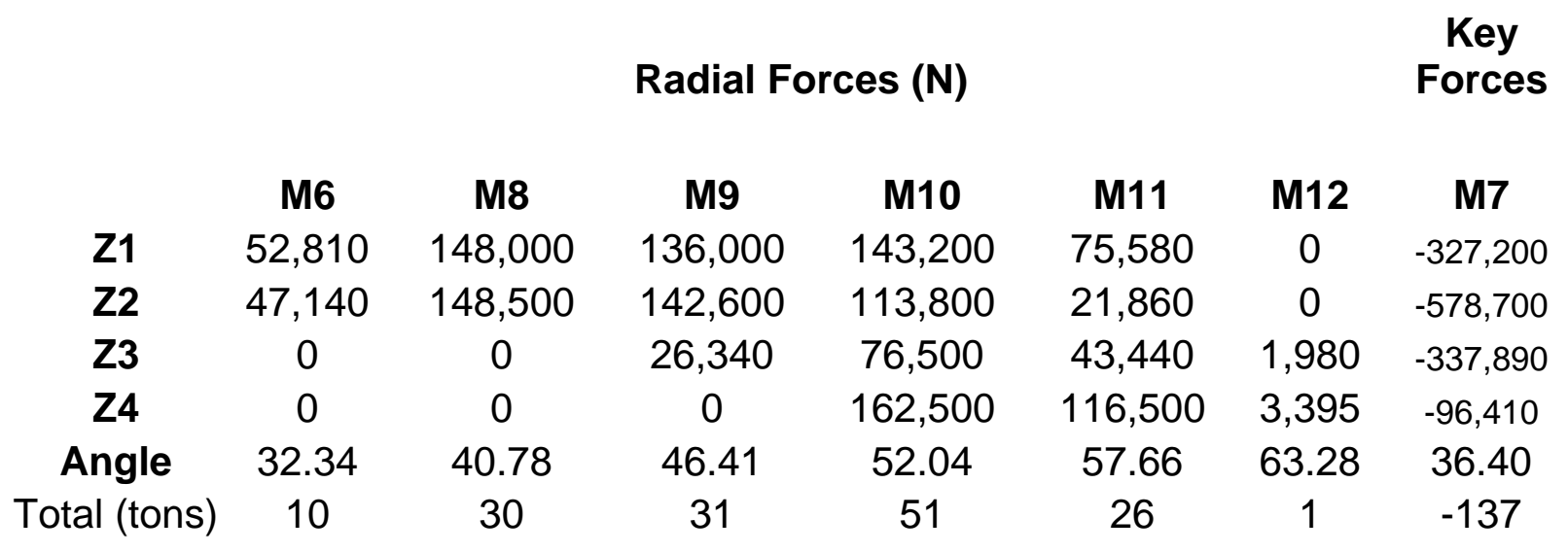


32 Modules in Place with Cryostat Load

Bottom Swivel Bolt Force $=18$ tons

Sum of Top Swivel bolt Force $=169$ tons

Angle to Centroid of Top Swivel Bolt Force=51.12 degrees

\begin{tabular}{|c|c|c|c|c|c|c|c|}
\hline & \multicolumn{6}{|c|}{ Radial Forces (N) } & $\begin{array}{c}\text { Key } \\
\text { Forces }\end{array}$ \\
\hline & M6 & M8 & M9 & M10 & M11 & M12 & M7 \\
\hline $\mathrm{Z1}$ & 60,450 & 149,800 & 146,900 & 152,600 & 78,240 & 0 & $-399,440$ \\
\hline $\mathrm{Z2}$ & 117,400 & 217,000 & 179,800 & 131,500 & 22,620 & 0 & $-680,000$ \\
\hline Z3 & 0 & 13,480 & 123,200 & 77,770 & 35,620 & 1,186 & $-427,700$ \\
\hline Z4 & 0 & 0 & 34,960 & 178,800 & 110,800 & 533 & $-142,900$ \\
\hline Angle & 32.34 & 40.78 & 46.41 & 52.04 & 57.66 & 63.28 & 36.40 \\
\hline Total (tons) & 18 & 39 & 49 & 55 & 25 & 0 & -168 \\
\hline
\end{tabular}

48 Modules in Place with Cryostat Load

Bottom Swivel Bolt Force $=31$ tons

Sum of Top Swivel Bolt Force $=222$ tons

Angle to Centroid of Top Swivel Bolt Force $=50.19$ degrees

\section{Radial Forces (N)}

Key Forces

$\begin{array}{cccccccc} & \mathbf{M 6} & \mathbf{M 8} & \mathbf{M 9} & \mathbf{M 1 0} & \mathbf{M 1 1} & \mathbf{M 1 2} & \mathbf{M} 7 \\ \text { Z1 } & 85,490 & 181,900 & 169,800 & 169,300 & 82,360 & 0 & -500,390 \\ \text { Z2 } & 187,000 & 287,200 & 225,000 & 159,700 & 28,670 & 0 & -841,300 \\ \text { Z3 } & 32,700 & 169,000 & 169,300 & 93,580 & 37,560 & 0 & -594,500 \\ \text { Z4 } & 0 & 0 & 83,900 & 201,400 & 117,400 & 0 & -251,300 \\ \text { Angle } & 32.34 & 40.78 & 46.41 & 52.04 & 57.66 & 63.28 & 36.40 \\ \text { Total (tons) } & 31 & 65 & 66 & 64 & 27 & 0 & -223\end{array}$



64 Modules in Place with Cryostat Load
Bottom Swivel Bolt Force $=47$ tons
Sum of Top Swivel Bolt Force=268 tons
Angle to Centroid of Top Swivel Bolt Force $=49.88$ degrees

Radial Forces (N)

\section{Key \\ Forces}

$\begin{array}{cccccccc} & \text { M6 } & \text { M8 } & \text { M9 } & \text { M10 } & \text { M11 } & \text { M12 } & \text { M7 } \\ \text { Z1 } & 114100.00 & 216,300 & 194,100 & 188,900 & 88,190 & 0 & -595,200 \\ \text { Z2 } & 236,900 & 345,400 & 267,200 & 188,500 & 35,540 & 0 & -996,500 \\ \text { Z3 } & 110,500 & 248,300 & 209,500 & 115,700 & 41,490 & 0 & -740,800 \\ \text { Z4 } & 0 & 16,250 & 115,500 & 227,500 & 128,000 & 0 & -354,600 \\ \text { Angle } & 32.34 & 40.78 & 46.41 & 52.04 & 57.66 & 63.28 & 36.40 \\ \text { Total (tons) } & 47 & 84 & 80 & 73 & 30 & 0 & -274\end{array}$

The table below is a summary for comparison between the FEA model and the 2D static model. The 2D static analysis compares very accurately with the 3D FEA analysis. What is most interesting is the comparison between the stability angle calculated from the 2D analysis and the FEA angle. In comparing the FEA angle of the centroid of the top swivel bolt forces with the stability angle, we find that the stability angle is always less than the centroid angle, as expected. This shows that the bottom swivel bolt force should always be in compression.

\section{Summary and Comparison of the Bottom Swivel Bolt Force between the FEA Model and the Static Model for 48/50 degrees}

\begin{tabular}{|l|c|c|c|c|c|c|}
\hline & $\begin{array}{c}\text { Stability } \\
\text { Angle }\end{array}$ & FEA Angle & FEA Force & $\begin{array}{c}48 \text { Degree } \\
\text { Static Force }\end{array}$ & $\begin{array}{c}50 \text { Degree } \\
\text { Static Force }\end{array}$ & $\begin{array}{c}52 \text { Degree } \\
\text { Static Force }\end{array}$ \\
\hline 24 Modules & 51.05 & 51.86 & 10 & -20 & -1 & 14 \\
\hline 32 Modules & 49.9 & 51.12 & 18 & -12 & 9 & 27 \\
\hline 48 Modules & 48.4 & 50.19 & 31 & 2 & 31 & 52 \\
\hline 64 Modules & 47.6 & 49.88 & 47 & 16.6 & 50 & 77 \\
\hline
\end{tabular}

What is the implication for stability of the EB of this comparison between the 2D static analysis and the 3D FEA model? The comparison between the FEA model and the 2D static model would give confidence that the structure is stable and that the angle to the centroid of the top swivel bolts will remain high enough so that compression will always be maintained on the bottom swivel bolt. However, the graph at the beginning of this paper shows that even when the EB is completed, a potential failure scenario exists if the distribution on the top swivel bolts for some unknown reason were to shift and the centroid of the top swivel bolt forces were to drop to a shallower angle. Could such a shifting of forces occur, for example, during the movement of the EB and contact is made on the X-brackets or during an earthquake? Such a shift appears unlikely, because the structure appears to deflect and move in such a way as to distribute the forces on the swivel bolts, so that the location of the centroid remains above the stability angle at which contact is lost on the bottom swivel bolt. For example, shallow angles of the centroid would cause the saddles to rotate and lose contact at the bottom swivel bolt. This rotation, though, causes contact to increase on the swivel bolts that are higher on the saddle, thereby increasing the angle of the centroid of the upper swivel bolt forces. The 
structure, therefore, would come to some equilibrium that maintains a minimal contact on the bottom swivel bolt.

However, complete confidence in the stability of the structure can only be obtained if a static analysis could show that under all circumstances, contact is never lost on the bottom swivel bolt. Precautions, therefore, are needed for the unlikely event that centroid drops below the stability angle, at which contact is lost on the bottom swivel bolt. These precautions can take 3 forms.

First, during assembly, a tension connection between the saddles will insure stability. The analysis that is described in Appendix 1 shows that a tension connection between the saddles provides stability for very shallow angles of the top swivel bolt force centroid. The graph below shows how the tension load varies with the number of modules if there was not contact on the bottom swivel bolt. Positive values indicate tension, negative values indicate compression which cannot occur and indicates that contact will occur on the bottom swivel bolt. This graph shows that in the 2D model, the EB is stable after 54 modules, with the cryostat load and the centroid angle greater than 48 degrees. As discussed above, it is unlikely that the centroid angle will be shallower than 48 degrees. In the unlikely event that it is, then the force sensor on the tension connection between saddles will indicate tension with 64 modules in place, which would indicate that there is a problem that would have to be addressed. There is currently a chain system available that can provide 20 tons at the front and back of the saddles for a total tension load of 40 tons. Load cells will be applied to these chains so it is possible to measure the force on them. If the EB behaves as predicted by the FEA model, then these chains will never see any load. It is currently planned to apply the dummy cryostat load in several stages. Therefore, it should be possible to monitor the force on the chains and to detect immediately if they are being loaded, which would indicate that there is a potential problem. In addition, it is recommended that the chain be installed whenever the EB is moved, in order to protect against any unforeseen forces that could occur during movement. The two precautions described below would also be in place to handle any unforeseen shifts in the location of the upper swivel bolt force if the tension bracket between saddles were not in place.

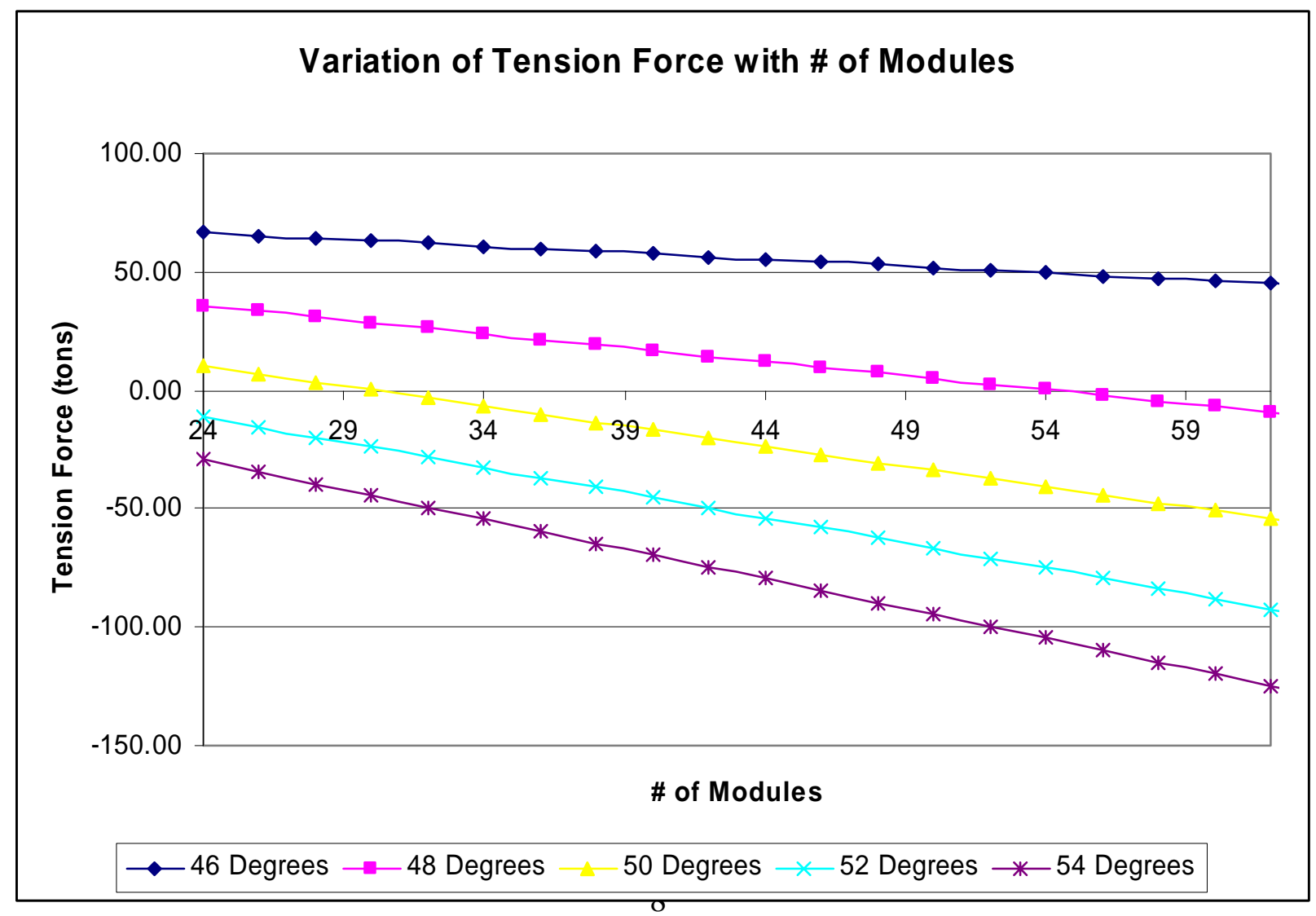


Second, once the structure is assembled completely, the tension brackets between the saddles and the modules at the location of the bottom swivel bolt provides the ability to take a tension load in this area. Each individual saddle has a tension bracket that is designed to resist a tension load of 20 tons, for a total of 40 tons tension per side. The graph at the beginning of this paper shows that slightly less than 40 tons tension at the bottom swivel bolt is needed with 64 modules in place if the centroid of the top swivel bolt force is at 46 degrees.

Third, the X-brackets, in essence, act like the tension chain when they are in place. The X-brackets are on the inside of the rail; therefore, if the saddles attempt to rotate because of the cryostat load, this rotation will be resisted by the X-brackets. This would be the case for both movement and, in the event of an earthquake.

\section{Conclusion}

The following conclusions can be drawn from this analysis.

- The analysis of the EB during assembly shows that it is stable.

- As an additional safety factor during assembly, a tension connection is needed between the saddles until 64 modules are in place. This tension connection needs to be able to withstand 40 tons tension, which corresponds to a centroid angle of 48 degrees.

- The tension connection should be in place whenever the EB is moved as an added safety factor to guard against unforeseen shifting of the swivel bolt forces. 


\section{Appendix 1 \\ Description of 2D Static Analysis}

A static analysis of the forces acting on the EB has been done to examine the forces on the saddle when the cryostat load is transferred.

The forces acting on the saddle in the back in this load case are shown in the figure below. Static equilibrium can be found using the following equations:

$\Sigma F_{y} \quad F_{1} \cos \theta+F_{2} \cos \alpha+F_{s} \sin \beta-F_{c}=F$

$$
\begin{gathered}
F=W+F_{c} \\
F_{1} \cos \theta+F_{2} \cos \alpha+F_{s} \sin \beta=W \\
\Sigma F_{x} \quad F_{1} \sin \theta+F_{2} \sin \alpha-F_{s} \cos \beta=0.0 \\
\Sigma M_{o} \quad-R F_{s}+X F-A F_{c}=0.0 \\
F_{s}=\frac{X F-A F_{c}}{R}
\end{gathered}
$$

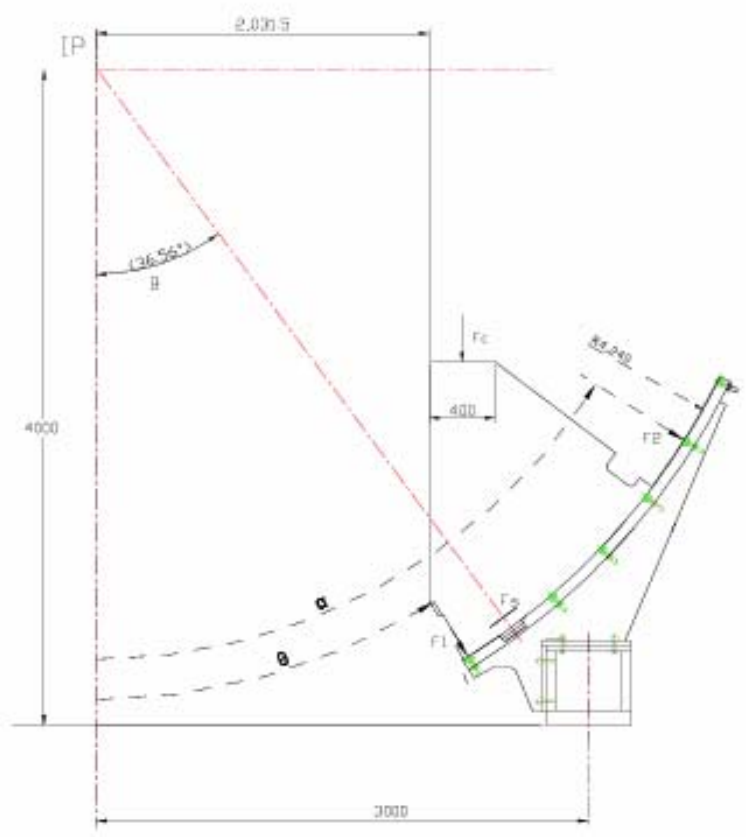

These equations can be used to solve for the swivel bolt forces, F1 and F2, and the key force, Fs. These forces depend upon the angle that is used to determine the location of the top and bottom swivel bolt. The bottom swivel bolt angle is fixed at 32.33 degrees. The angle of the top swivel bolt, though, can vary considerably, because this single force shown in the figure actually represents 5 swivel bolts. 
The force F2 represents the force acting at the centroid of the individual forces acting on these 5 swivel bolts.

The figure below shows how the value of the bottom swivel bolt varies as the angle to the centroid of the top swivel bolt varies. The force on the bottom swivel bolt is shown for the case of 24 modules with and without the cryostat load applied. It can be seen that the bottom swivel bolt is in compression for all angles when there is no cryostat load applied. However with the cryostat load applied, the force on the bottom swivel bolt becomes negative, indicating tension for angles below 50 degrees. Since the bottom swivel bolt cannot support tension, the saddle becomes statically unstable. This condition represents a failure scenario.

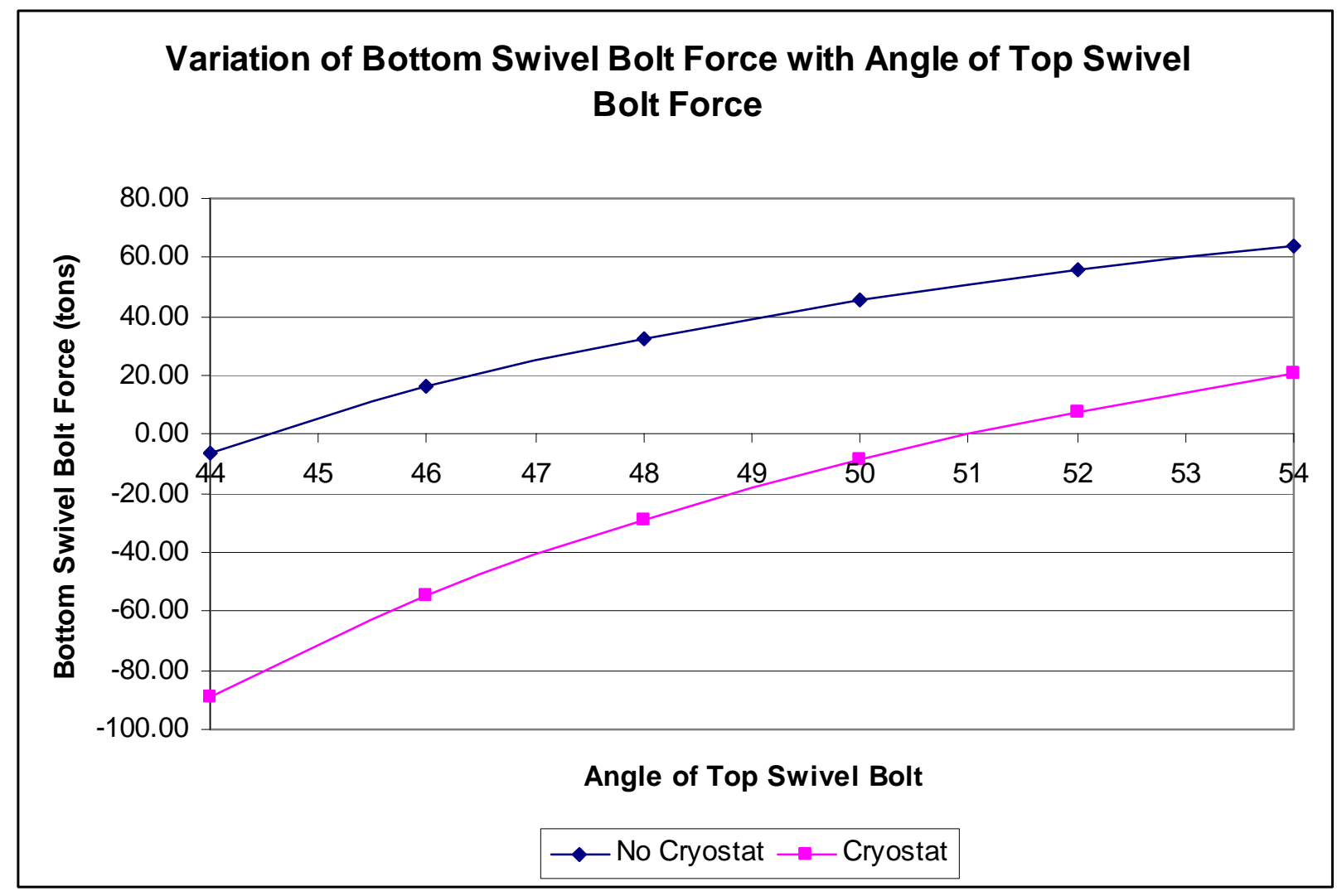

The static calculations were compared to the FEA model with 24 modules in place and the cryostat load applied. The centroid where the sum of the top swivel bolt forces are acting was calculated from the FEA model to be 49 degrees. A comparison is made in the table below between the FEA model and the static analysis at 49 degrees and 52 degrees. The static analysis at 49 degrees shows that the bottom swivel bolt will lose compression while the static analysis at 52 degrees shows very good agreement with the FEA model.

\section{Modules in Place with Cryostat Load Comparison of FEA and Static Analysis}

\begin{tabular}{|l|c|c|c|}
\hline & Static-49 degrees & Static-52degrees & FEA-49 degrees \\
\hline Key Force (tons) & 142 & 142.2 & 137.0 \\
\hline Top Swivel Bolt Force (tons) & 164 & 140.0 & 139.0 \\
\hline Bottom Swivel Bolt Force (tons) & -18.3 & 7.2 & 10.0 \\
\hline
\end{tabular}


The results for the FEA model are a summary of the forces along $\mathrm{Z}$ at each swivel bolt. For the top swivel bolt force, the 139 tons shown is the sum of all the swivel bolts above the key and the centroid of where these forces were acting was calculated to be 49 degrees. The actual distribution of the swivel bolt forces from the FEA 3D model is shown below:

Radial Forces (N)

\begin{tabular}{|c|c|c|c|c|c|c|c|}
\hline & M6 & M8 & M9 & M10 & M11 & M12 & M7 \\
\hline Z1 & 52,810 & 148,000 & 136,000 & 143,200 & 75,580 & 0 & $-327,200$ \\
\hline $\mathrm{Z2}$ & 47,140 & 148,500 & 142,600 & 113,800 & 21,860 & 0 & $-578,700$ \\
\hline Z3 & 0 & 0 & 26,340 & 76,500 & 43,440 & 1,980 & $-337,890$ \\
\hline Z4 & 0 & 0 & 0 & 162,500 & 116,500 & 3,395 & $-96,410$ \\
\hline $\begin{array}{l}\text { Angle } \\
\text { Total }\end{array}$ & 32.34 & 40.78 & 46.41 & 52.04 & 57.66 & 63.28 & 36.40 \\
\hline (tons) & 10 & 30 & 31 & 51 & 26 & 1 & -137 \\
\hline
\end{tabular}

M6 is the bottom swivel bolt, M8 is the swivel bolt directly above the key and M12 is the top swivel bolt. Z1 is the set of swivel bolts at the front of the EB and Z4 is the set of swivel bolts at the back of the EB where the back cryostat load is applied. All of the forces shown are in Newton's except the bottom row, which is the sum of the forces along $\mathrm{Z}$, which is in tons. This 3D distribution of the swivel bolts shows that the bottom swivel bolts on the back saddle lose contact and that only the bottom swivel bolts on the front saddle maintain contact when the cryostat load is applied with 24 modules in place. Another interesting feature of this 3D distribution of the swivel bolt forces is that the centroid of the upper swivel bolt forces on the back saddle (Z3-Z4, M8-M12) is acting at an angle of 54 degrees. The centroid of all of the forces summed in Z and from M8-M12 is 49 degrees. This indicates that as the saddles rotate and contact is lost on the bottom swivel bolt, the saddles will begin to make contact at a higher angle in order to maintain static equilibrium.

Even though the FEA model shows that the swivel bolt forces are distributed in such a way that the structure is stable, it is prudent to have in place fixturing that can prevent the potential failure scenario described above from occurring. Because of some unforeseen event such as improper mounting of the saddles, failure of a swivel bolt, the dynamic loading of the cryostat, the centroid of the top swivel bolt could potentially be low enough so that the bottom swivel bolt force becomes zero or negative. In such a case, the structure will become unstable.

One proposed solution is to have the tension connection shown in the figures below. 

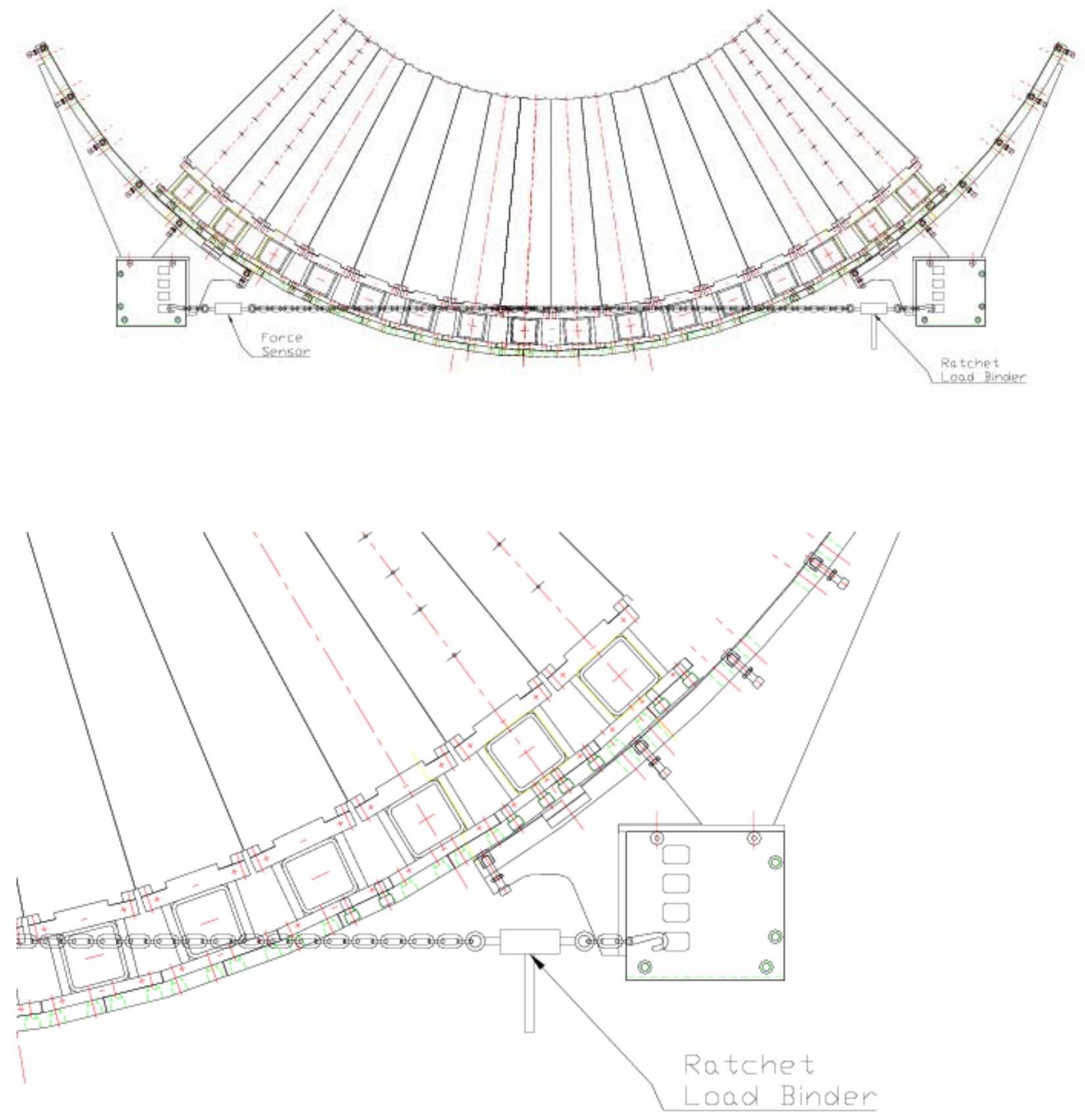

The forces acting on the saddle in this situation are shown in the following figure. 


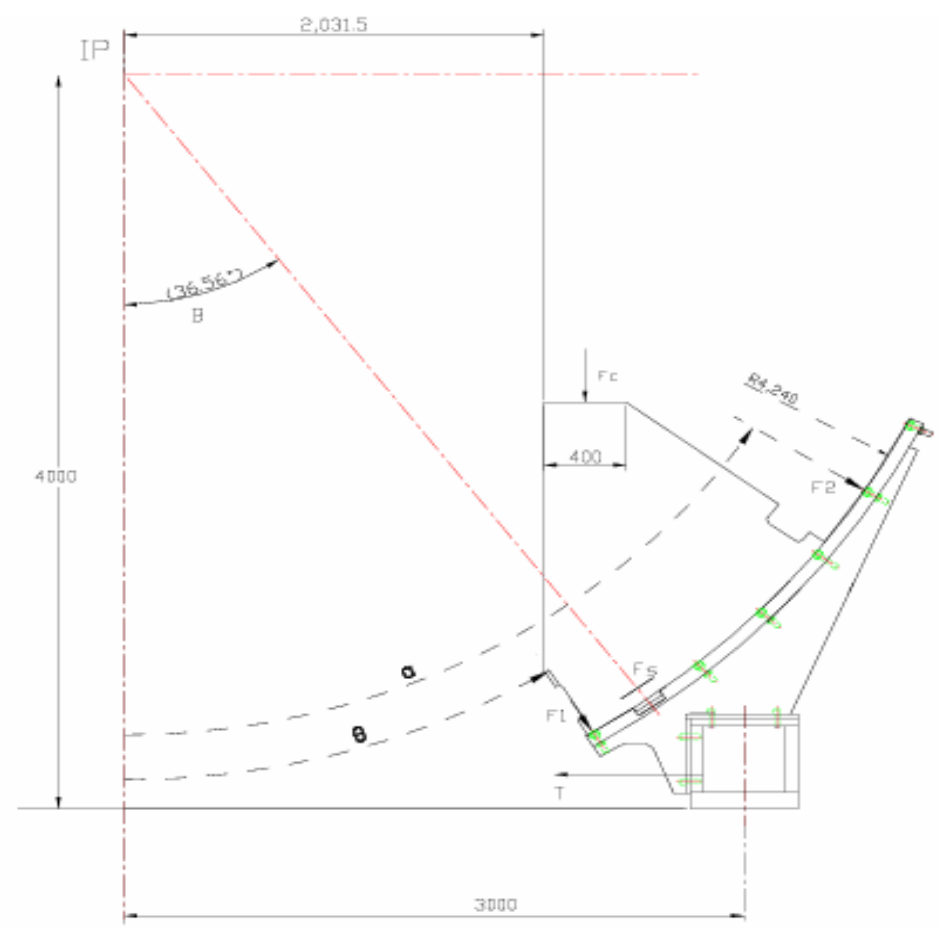

The following loading scenario is envisioned. Initially the cryostat load is not applied and the force on the bottom swivel bolt falls along the blue line in the graph above. Next, the cryostat load is applied. When the cryostat load is applied the centroid of the forces acting on the top swivel bolts may be acting above 50 degrees as indicated by the 3D FEA model. If this is the case then the bottom swivel bolt will be in compression and its value will fall along the pink line in the graph above. However, if the centroid of the forces falls below 51 degrees then the structure becomes unstable because the force on the bottom swivel bolt becomes negative, indicating tension. In this case contact will be lost on the bottom swivel bolt and the chain indicated will begin to carry some load. A static calculation was done with the bottom swivel bolt force, F1, equal to zero and the tension force in the chain, $\mathrm{T}$, as an unknown. The value of the tension force is plotted versus the angle of the centroid in the figure below. 


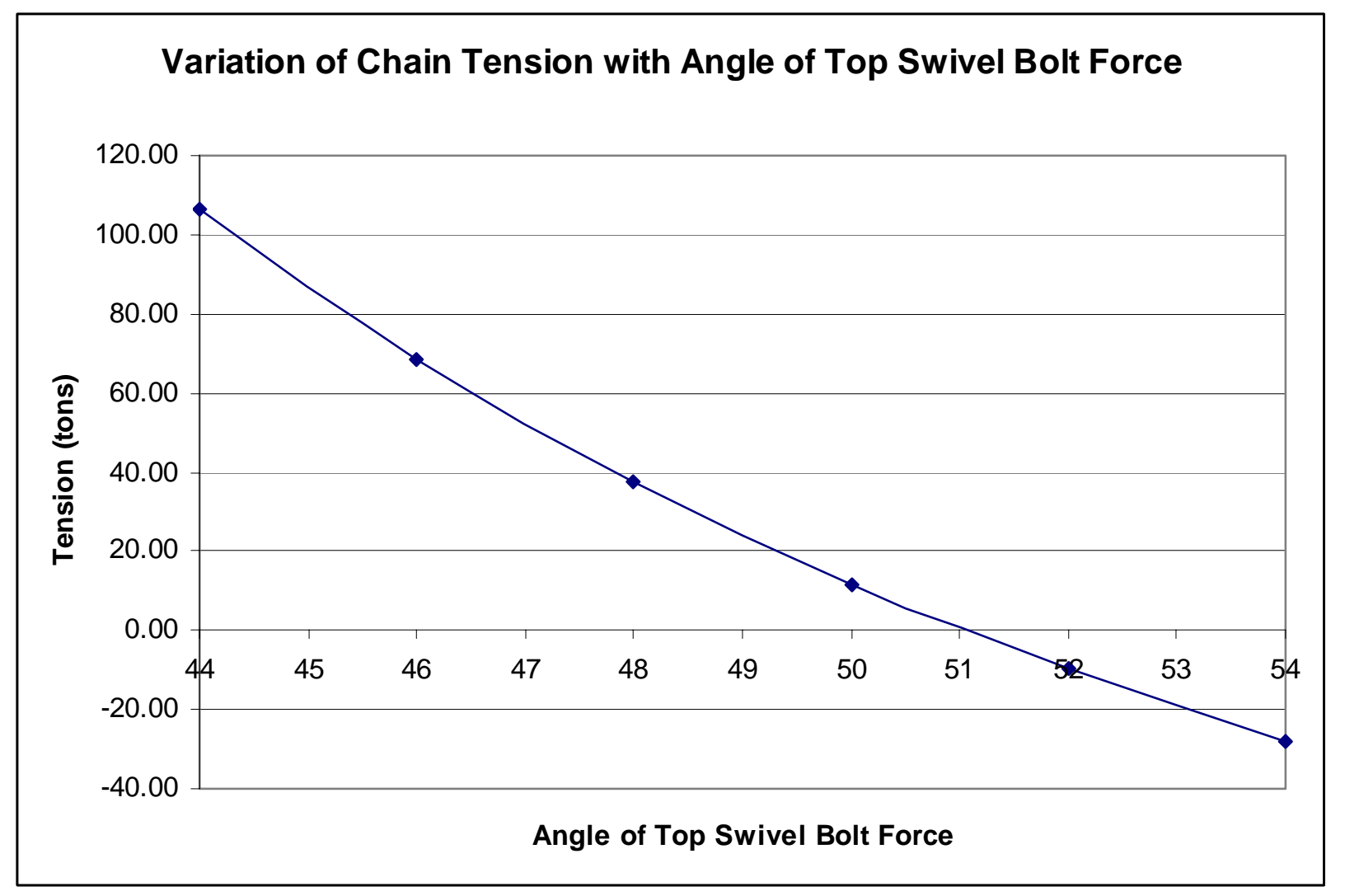

\section{Variation of Chain Tension with Angle of Top Swivel Bolt Force 24 Modules in Place}

This graph shows that as the angle of the centroid of the top swivel bolt forces increases from 44 degrees to 54 degrees the tension in the stability chain declines. At 51 degrees the force on the chain goes from tension to compression. This corresponds with the transition for when the bottom swivel bolt force goes from compression to tension. Therefore, the chain will only be under load if compression is lost on the bottom swivel bolt.

In addition, there are several ways to provide stability while keeping the chain force to a relatively small load of approximately 20 tons. First, the tension brackets between the saddles and the modules can be used to apply a tension load at the bottom swivel bolt. The tension bracket can support a tension force of 40tons in the region of the bottom swivel bolt. If the maximum tension in the chain is kept at 20 tons then the load on the bottom swivel bolt is shown in the figure below. 


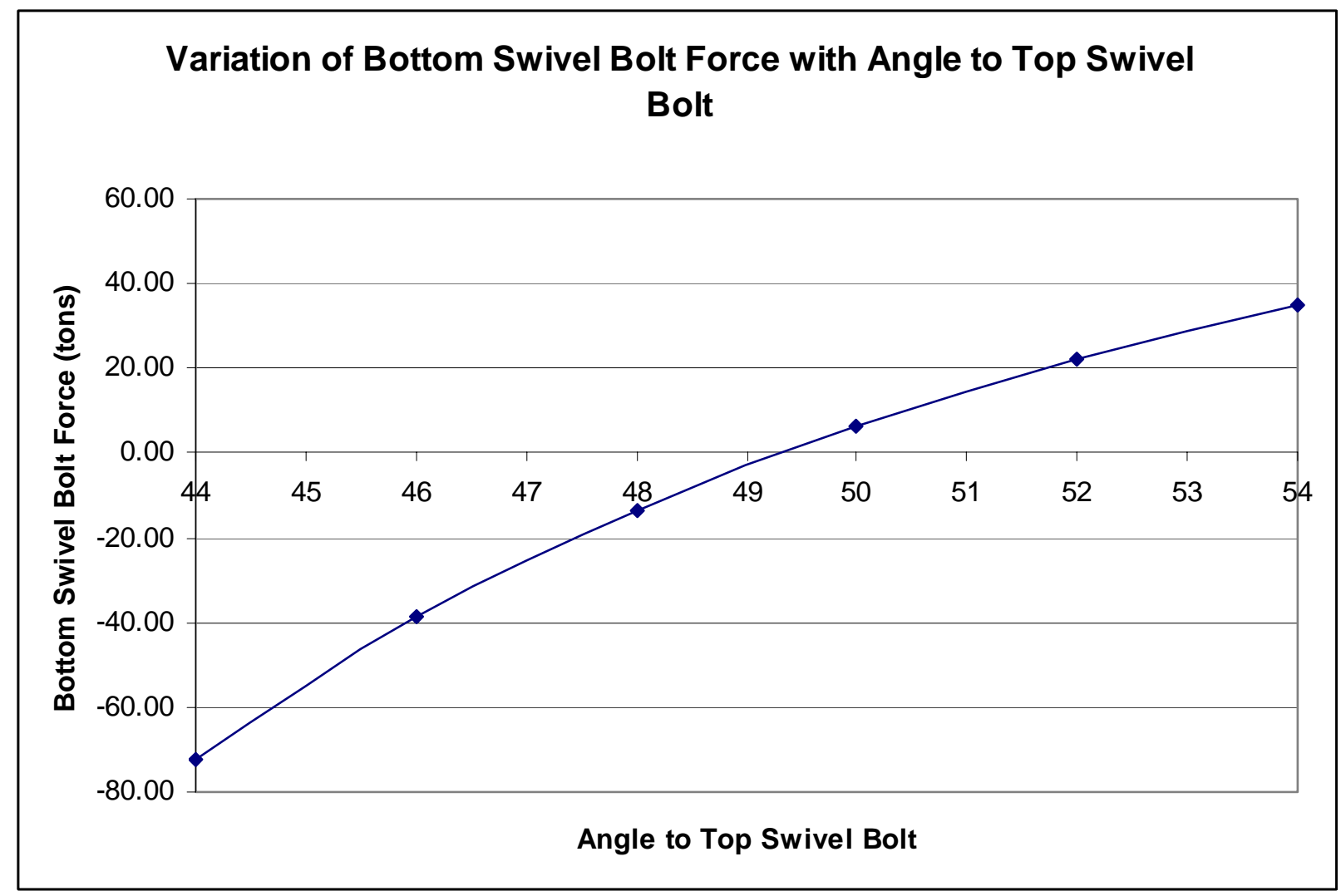

The tension load on the bottom swivel bolt is greater than 40 tons for angles less than 46 degrees. 